\title{
Innovative Approach to Improving the Efficiency of Labor Potential: Talent Management
}

\author{
I.N. Makhmudova ${ }^{1, *}$, L.L. Kifa ${ }^{2}$, and S.E. Vasilieva ${ }^{3}$ \\ ${ }^{*}$ Corresponding author: Mahmudova.I@yandex.ru. \\ ${ }^{1}$ EDP Samara State University of Economics, Samara, Russia \\ ${ }^{2}$ Togliatty National Research University, Russia \\ ${ }^{3}$ Togliatty National Research University, Russia
}

\begin{abstract}
The paradigm of the personnel management concept has been changed based on the introduction of digital technologies in the labor process. The article reveals the impact of new information technologies on the formation and usage of laborpotential in the renewed organizations. The new approach is not knowledge management, but talent management. The socio-psychological analysis of the structural elements of labor potential is also used. Terminological definiteness of such concepts as loyalty and reliability of employeesis carried out according to their participationactivity in the labor process. Distinctions of highly professional (HiPro) and high-potential (HiPo) personnel are given. High level of motivation among high-potential employees is emphasized as a condition that increases the level of labor potential efficiency. The role of employees' involvement in the formation of the personnel reserve is defined. Modern tools, based on digital platforms, developing labor potential were used. The mechanism of HR-technologies is revealed, in which an employee with greater potential is unable to reveal his labor potential, and becomes a brake for the innovative development in organization. There was named the principal responsibility for timely and qualitative formation of the new competencies, required for realizing the labor potential, in terms of updated reality.
\end{abstract}

Keywords: labor potential, talent management, loyalty, trustworthiness, engagement, labor activity.

\section{Introduction}

According to the long-term economic development strategy of the domestic economy in the period up to 2020-20252030, the task to modernize traditional sectors of economic growth and to form a digital economy focused onhigh technology was stated $[1 ; 2]$.

The understandingof the importance to measure the potential employees'capacityis coming, while the new socioeconomic relations in society, the introduction of modern digital technologies in production and training, the actualization of new professional competencies, in accordance with the development strategy of updated organizations and their business ideas, are forming. Solving of these issues leads to a change from the personnel management concept to the human resources managementapproach, to the formation and accumulation of intellectual capital in organizations.

The assessment of labor potential has already been led to a transition from knowledge management to talent management. Similarly, all components of labor potential, their essence and measurement technology, using advanced cloud solutions, have become more complex.

\section{Problem Statement}

Recent years have been marked by a sharp decline in the efficiency of the labor potentialuse, low personnel motivation to highly productive work, lack of experienced specialists, a large amount of unstructured data, errors in the financial forecasting of HR strategy. In this regard, there is an increase in employee dissatisfaction with work, staff turnover and, as a consequence, a dramatic decrease in the loyalty of the organization's staff.

The process of forming the information and innovation economy obliges organizations to keep the most accurate account of the quantity and quality of available resources, as well as to redistribute them with maximum efficiency. In this regard, special attention is paid to the assessment of the labor potential and the effectiveness of its use in technologically new conditions.

\section{Research Questions}

Today, it can be noted that the task of providing the organization with highly professional personnel has failed. Objective reason is that on the labor market there is no suitably qualifiedstaff with appropriate skills to the modern cloud (digital) technology. That is why supportingthe organization with skilled employees, at the right time and in the right place, is essential for the creation of a coherent and logical talent management system. In this regard, it is required to have innovative approach to the management of thelabor potential and ensuring the flexibility of the entire HR system in accordance with objectives of the business. To do this, it is necessary to identify a modern view at an issue of 
developing the employees' potential, so it will be possible to manage all HR-processes from one system and improve the efficiency of the organization's staff. In addition, a new approach is needed to identify the problems that cause a decrease in personnel activity in the implementation of the labor potential in the renewed workplaces.

\section{Purpose of the Study}

Creating such a holistic, transparent talent management strategy, integrated into all elements of the organization's HR management system, is impossible without terminological certainty. For example, you should understand who is a"high-potential"HiPo-employee, and whether it can be included in the"talent pool"? How trustworthy will he be, and what level of loyalty should we expect from him? How is it different from professional HiPro employee? Who has a higher degree of labor activity and / or more consistent with the modern business process strategy of the organization?

The question of loyalty and reliability of the staff arose not by chance. The level of staff loyalty is closely related to the turnover rate. Loyal staff should not be mistaken with trustworthy labor. Trustworthiness of personnel reveals the degree of normative behavior in relation to the company. Itseeks to comply with all the rules and regulations established in the company. But in the case of unfair treatment by the management or mismatch of his personal interests and the interests of the company, is able to commit an illegal act against the company [3].

Staff loyalty is characterized by a positive attitude of the employee to the activities, policies, management of the company. The basis of theloyal employee's behavior is their desire to benefit the company and avoid actions that can harm it. The highest degree of employee loyalty is when it perceives the company's affairs as its own business. A loyal employee, on the one hand, deeply accepts some of the requirements of the company, and on the other hand, is ready to put up with others that do not quite suit him [4].

In fact, trustworthy personnel are passive in the manifestation of their labor potential. They take a "wait-and-see" attitude in assessing the benefits that provided to them in the workplace by leaders of the organization. Such employee can be referred to a "highly professional"HiPro-employee. However, in terms of technological change, when it is necessary to search for innovative approaches and working methods, to operate semi structured data, to master modern tools and technologies, requiring a proactive attitude to perform assigned tasks, just to comply with the requirements and regulations of labor discipline, positive attitude to company policy - it means 'to stand still', and, in fact, inhibit innovation. A highly professional HiPro-employee uses past experience, which, at best, may not fit into a new relationship, and at worst - to spoil innovative initiatives.

Loyal staff may not fall into the category of "highly professional"HiPro-employees, however, due to high motivation, they are ready for any tasks in the updated reality. They have an inquisitive mind and ready to search for non-standard solutions, because they are not burdened with experience and imposed decisions (rules, outdated norms). They are proactive in finding answers, for which they are ready to growth rapidly, always up to master and use modern technologies in their work to get a positive result for the organization.

However, high level of motivation is important condition to be a "high-potential" HiPo-employee. To stimulate active and proactive attitude to work, it is necessary to bring HiPo-worker to the level of partnership, co-management of the organization's business, to increase the level of his involvement. He should understand his personal benefit, and not in the form of a one-time compensation/premium, butin the prospects for his personal development. It should not be a nominal, but a real "personnel reserve" in accordance with the performance evaluation, which reflects the level of achievement of the employee's business objectives. He is personally responsible for the formation of his competencies needful to work in a renewed environment.

Today, the task to motivate employees is shifting towards greater opportunities for providing self-realization, professional growth and career building within the company. According to KPMG research, improving the efficiency of organizations in Russia is becoming a higher priority, which is achieved by increasing employee engagement (55\%) and talent management (51\%) [5].

Betting on HiPo-workers, employers develop internal training in the format of distance e-learning courses, and are willing to invest in this process, despite the general trend of reducing the HR budget. The main requirement, at the same time, is compliance with two sources: job success profile and skill-matrix, which give a detailed description of the professional skills for particular position.

Following the annual planning system of employee development (progress development guide, PDG), companies use this electronic document (on SAP platform) in which the employee independently and/or with the support of the leader conducts self-assessments (approved by the company's competency model) and is working on a plan of his improvement. Assessing of the labor potential usually follow two criteria: sustained performance (stability of results) and potential level (potential level from 1-level inconsistencies up to 3 maximum). As a result, the employee comes to a certain category in terms of talent development.

However, it is important to strike a balance, engaging an employee in management and self-evaluation processes. The activity of the employee in the process of involvement can dramatically decrease in the state of overload, accumulation of fatigue, not getting an assessment of the results that were achieved, loss of the prospects for their own growth. An employee may experience professional burnout, develop dissatisfaction with work. A loyal employee, losing activity, once again goes into the category of trustworthy, soothing, passive. If the burnout process has gone too far, such an employee is dismissed, the turnover rate increases. The employee is either looking for a new place to use 
their accumulated abilities, and the company becomes a "forge of personnel", or goes into the underground (changes the scope of professional activity).

\section{Research Methods}

The developed technology, innovative approaches in the formation and use of labor potential in the updated environment are based on the analysis and comparison of research results published for open use in the Internet environment. The basis for tasks-solving has been put the author's studies either [6-11], that were carried out with the aim to identify specific competencies HiPo (high potential) and HiPro (high professional), relevant digital technologies. The author's method of competence assessment [6] is used to measure the level of labor activity, identify new trends and patterns of competence formation of 'end-to-end' technologies in the implementation of the labor potential.

\section{Findings}

Based on the above, we can highlight several important points.

Referring to the labor potential, it is necessary to bear in mind not a set of certain knowledge and even performanceexperience of professional duties, which in itself is important, but the degree of active and proactive use of them by the employee in solving the tasks.

The level of activity is achieved through the provision of opportunities to engage in self-development, using advanced cloud technologies (in the format of remote e-learning courses), through which the employee can be involved in the process of co-management of the organization. At the same time, he must be extremely goal-oriented, understand his role and level of participation in the business process, which is determined by the formation of relevant competencies. The type and list of modern competencies is determined and approved by the management of the organization for each specific business task.

The required competency level is assessed according to the HiPo "formula" proposed by SHL for capacity assessment. It includes only three terms [4]:

1. Striving for achievements (potential to take a managerial position),

2. Abilities (questionnaires, Hogan, Talent Q),

3. Involvement (potential assessment - test PiF, Potential in Focus),

At the same time, it is much more important not just to assess the labor potential, but, following the results of the evaluation, to bring information about the enrollment of the person in a particular group at the HiPo level. This is an indicator of forming the employee's labor potential, the effectiveness recognition of his work and success in the personal trajectory implementation of its development within the organization. Enrollment in a certain HiPo group gives an idea of the formed personnel reserve in the organization and the personal benefits that, in this regard, may be available to a particular employee. In this case, the factor of motivational interest determines the level of personnel responsibility in the development of their own labor potential.

The main problem in the functioning of this system is that both the management and the employee, due to different circumstances, can force this process. This has a negative impact on the health of the employee. He is overloaded with work, authority and, sooner or later, there is a professional burnout. This leads to disappointment, dissatisfaction, reduced loyalty of the organization. That is, the employee loses valuable quality HiPro its qualitative characteristics, while remaining highly professional.

\section{Conclusion}

Thus, it is important for managers not only to provide a cumulative system of forming professional qualities among HiPo-employee in accordance with new technologies of personnel management and business environment. But also necessary to define the figures and indicators, by which it is possible to determine the moment of loss-professional burnout, reduction of employee loyalty, its initiative activity in solving tasks. All this will contribute to the disclosure of the labor potential of staff.

\section{References}

1. Federal law "About the independent skills assessment" of 3 July 2016 N238-FZ (2016). URL: http://www.consultant.ru/document/cons doc LAW 200485/. Accessed: 01.09.19. [in Rus.].

2. Passport of the national program "Digital Economy of the Russian Federation" (approved by the Presidium of the Presidential Council for Strategic Development and National Projects on December 24, 2018, N16) (2018). URL: http://base.garant.ru/72190282/. Accessed: 01.09.19. [in Rus.].

3. I.N. Makhmudova, Y.A. Krivoruchko, From unreliability to staff loyalty to ensuring the safety of organization personnel. Kadrovik, 7, 93-100 (2019). [in Rus.]. 
4. A.A. Borzunov, The importance of human resources to ensure the economic security of the company in the transition to the digital economy. Vector Economy, 7 (2017). http://www.vectoreconomy.ru/index.php/number7/economicmangment-7-2017. Accessed: 01.09.19. [in Rus.].

5. K. Laktionova, Potential employees: The illusion and reality. Spravochnik Kadrovika (2015). URL: https://www.propersonal.ru/article/1083934-qqe-m12-potentsial-sotrudnikov-prizrachnost-i-realnost. Accessed: 01.09.19. [in Rus.].

6. I.N. Makhmudova, The methodology of competency assessment of staff to determine professional standards. Scientific Review: Theory and Practice, 1, 59-74 (2017). [in Rus.].

7. I. Makhmudova, E. Belonogova, Using digital technologies in staff training. Slovak International Scientific Journal, 1(16), 19-22 (2018).

8. I.N. Makhmudova, S.I. Zhuchenko, Unclaimed employment in the digital economy. In G.Yu. Gulyaev (Ed.), Proceedings of the V International Scientific and Practical Conference "Economics and Management in the XXI Century: Sustainable Development Strategies» (pp. 84-87). Penza: ICNS “Science and Education" (2018). [in Rus.].

9. L.A. Ilyukhina, I.V. Bogatyreva, I.N. Makhmudova, J.D. Ermakova, Development of a corporate personnel training system: the experience of Russian enterprises. In: V. Mantulenko (Ed.), Proceedings of GCPMED $2018-$ International Scientific Conference "Global Challenges and Prospects of the Modern Economic Development", The European Proceedings of Social and Behavioural Sciences EpSBS, LVII (pp. 654-665). London: Future Academy (2019). DOI: 10.15405/epsbs.2019.03.65.

10. L.L. Kifa, I.V. Kryuchkova, On the issue of staff development trends. Azimuth of Scientific Research: Economics and Management, 4(17), 175-177 (2016). [in Rus.].

11. L.L. Kifa, Features of certification of senior employees of municipal institutions in the transition to an effective contract. Vector Science of Togliatti State University. Series: Economics and Management, 2(29), 54-59 (2017). [in Rus.]. 